\title{
(META)CURADORIA EM \\ PROCESSOS DE MUSEOLOGIA SOCIAL
}

\author{
Marijara Souza Queiroz* \\ Universidade de Brasília
}

\section{RESUMO}

Este artigo é um compilado de reflexões sobre ideias associadas a práticas e processos de museologia social desenvolvidos na Casa dos Movimentos da Estrutural, DF (20| I-20I4), aqui chamados de metacuradoria. Pressupõe-se que tais práticas museológicas contribuem para a quebra do que seria a curadoria tradicionalmente conhecida e das normas expográficas a ela relacionadas. A metacuradoria, por sua vez, seria o exercício crítico, a articulação de narrativas plurais e a relação dialógica entre o público e $\circ$ trabalho ou tema da exposição. Ela apresenta questões sobre a construção de discursos e suas formas de representação na exposição a fim de propor o contraponto à ordem hegemônica como uma das principais dimensões da ação museal para o desenvolvimento social.

\section{PALAVRAS-CHAVE}

Metacuradoria; Museologia social; Discursos; Exposições.

\begin{abstract}
This article is a compiled of reflections about metacurating ideas associated to practices and social museology processes developed in the House of Structural Movements, DF (20112014). It assumes that such museological practices contribute to the breakdown of curatorial and expographics standards, in order to approach the metacuradoria ideas that, in turn, is the critical exercise, the articulation of plural narratives and dialogical relationship between public and work or theme of the exhibition. It presents questions about the construction of utterence and their forms of representation in the exhibition, in order to propose the overthrow of that order against hegemonic as one of the main dimensions of the museum action towards social development.
\end{abstract}

\section{KEY-WORDS}

Meta-curation; Social Museology; Discourses; Exhibitions.

\footnotetext{
" Professora Assistente do Curso de Museologia da Faculdade de Ciência da Informação da Universidade de Brasília. Mestre em Artes Visuais pela Escola de Belas Artes da Universidade Federal da Bahia. Graduada em Museologia pela Faculdade de Filosofia e Ciências Humanas da Universidade Federal da Bahia.
} 
O objeto de estudo deste artigo é a metacuradoria', que se traduz como reflexão e postura crítica à cerca de padrões radicados nas formas de expor, e suas ressonâncias no campo da museologia social ${ }^{2}$, que se caracteriza como uma tendência de parte do campo museal que se avigora para ajustar as bases museológicas às condições da sociedade contemporânea. Parte da hipótese central de que os processos e as práticas sociais da museologia corroboram com a quebra de paradigmas curatoriais e expográficos, de modo a aproximar-se das ideias de metacuradoria que, por sua vez, consiste no exercício crítico, na articulação de narrativas plurais e na relação dialógica entre público e obra ou tema abordado na exposição.

Poucos estudos são dedicados à ideia de metacuradoria, como também à curadoria, na condição de uma das dimensões do sistema da arte, conectada às práticas expográficas desenvolvidas a partir dos processos de museologia social. No interim, interessa-nos ainda refletir sobre a ideia de museologia social, partindo do pressuposto que esta, ao idealizar elaborações de exposições participativas em comunidades e grupos sociais periféricos e populares, subverte a ordem dos discursos possibilitando a crítica e o questionamento dos modelos convencionais de expor.

Importa ainda trazer para o centro deste debate as práticas contemporâneas de museologia social associadas à metacuradoria como ação afirmativa e proposta contra hegemônica para exposições museológicas. Portanto, aponta para a necessidade de preenchimento de uma lacuna importante nos processos de produção de conhecimentos acerca da teoria e história da curadoria como dimensão do sistema de arte, bem como sua aplicabilidade técnica através da exposição museológica. Ademais, inaugura o desejo de aproximação entre as duas áreas - metacuradoria e museologia social - que surgem na contemporaneidade como resultado de experimentos multidisciplinares.

\section{Questões sobre (Meta)Curadoria}

A curadoria pode ser compreendida de modo geral como a concepção, o planejamento e muitas vezes a coordenação da montagem de uma exposição. Em outros casos, a curadoria significa a composição de um acervo histórico, artístico ou cultural a partir de determinado recorte - temporal, geográfico ou estilístico - dentre outras possibilidades. É, neste caso, a criação ou o alinhavo de narrativas e discursos que atribuam significados ao conjunto das obras expostas ou a cada uma delas individualmente.

Este artigo conduz às discussões teóricas à cerca da curadoria e seu processo histórico de transformação até a tessitura da ideia de metacuradoria. Entretanto, no recorte aqui proposto, trataremos das questões que delineiam o tema. Nesse sentido, segundo José Teixeira Coelho Netto (2004, pag. I40-I4I), na origem do termo, curadoria se referia ao processo de organização e montagem de exposição de um conjunto de obras de um artista ou conjunto de artistas. Cabia ao curador tratar de todos os detalhes necessários à operação, cuidar da administração da mostra e de seus diferentes aspectos.

\footnotetext{
'No contexto acadêmico, a ideia de metacuradoria traduz-se numa postura de autocrítica e de comprometimento com a renovação científica, cultural e artística. Isso significa questionar modelos cristalizados, propor questões, pautar debates, levantar dúvidas, abrir-se às demandas da sociedade e dar subsídios à formulação de políticas públicas. (IEA/USP, 20l6).

${ }^{2}$ Museologia social é um movimento da Museologia que visa estimular o desenvolvimento de museus ou processos museais diretamente nas (e com as) comunidades pelo direito de elas decidirem o que deverá ser preservado. Pode ser compreendida como uma ação de reparação às lacunas deixadas pelos museus clássicos que historicamente se preocuparam mais em representar os grupos hegemônicos da sociedade. Como processo ou prática voltados para o desenvolvimento social, não depende do museu institucionalizado ou físico para que a ação sócio museológica ocorra. (Queiroz, 2015).
} 
$\mathrm{Na}$ transformação do conceito, Coelho Netto observa que curadoria é a tarefa que determina o tema inspirador de uma exposição e de selecionar artistas e obras a partir dessa escolha. Neste caso, as obras e os artistas tornam-se instrumentos para demonstração, em geral de confirmação, da tese defendida. Artista e obra era o ponto de chegada da exposição.

Numa discussão atemporal, Coelho Netto não apresenta o contexto histórico que favoreceu a evolução do termo curadoria, mas complementa que "tendências pós modernas de valorizar o crítico e o historiador da arte e de colocá-los em pé de igualdade com o artista" marcam um "novo" (de quando?) entendimento da palavra curadoria que reconduz ao "velho" (de quando?) entendimento jurídico onde o curador é aquele que por "incumbência legal tem a função de zelar pelos bens e interesses dos que por si não o possam fazer". Assim, o curador não mais apresenta ou descobre artistas, cria movimentos inteiros e dão rumos à produção artística.

Observamos, no entanto, que algumas instituições museológicas adotam ainda a curadoria como uma das dimensões associadas à gestão de coleções, ao incumbir técnicos específicos para os cuidados de coleções específicas como pintura brasileira, pintura estrangeira, fotografia, arte africana, escultura brasileira, dentre outras. Este é o caso, por exemplo, do Museu Nacional de Belas Artes (MNBA), Rio de Janeiro, onde cabe ao curador de cada coleção não apenas zelar pela sua preservação, o que inclui ações de registros e pesquisas relacionadas às peças individualmente e no conjunto - bem como às possibilidades de articular discursos que as associem a outras coleções. Na prática, significa uma especialização em determinada tipologia de coleção, a partir da vivencia cotidiana e preferencialmente prolongada entre o curador e a coleção. Para o Instituto Brasileiro de Museu, autarquia a qual o MNBA está vinculado, curadoria é uma

Atividade relacionada ao profissional responsável por preservar, gerir e divulgar um acervo e /ou coleções. $\bigcirc$ trabalho de curadoria envolve o conhecimento sobre o tema a ser exposto, pré-seleção do acervo, definições de como os objetos selecionados serão expostos no ambiente, estabelecimento de como será o diálogo com o público durante a exposição e as ações educativas, dentre outras práticas relacionadas à administração do acervo. (Museália, 20 I 0:52).

Nesse sentido, cabe questionar: porque convida-se curadores externos, geralmente intitulados curadores pela fluência do transito - técnico, intelectual e pessoal - no cenário artístico, se o curador ideal, de acordo com esse modelo de curadoria por especialização, é aquele que melhor conhece a coleção? O curador de arte é neste caso $O$ Grande Curador? Se sim, devemos considerar invalidada toda e qualquer especialização em outras dimensões do conhecimento que não seja o artístico para a formação e reconhecimento do curador de exposições?

Este modelo de curadoria se aproxima ao que Betina Rupp (201 I: 136) denominou de "curadoria de coleções" ou "curadoria tradicional" que pode ser traduzida como aquela em que o curador, que preferencialmente deve estar vinculado a uma instituição, atua como conservador e organizador de uma coleção. Nesse caso o curador passa a contar com as vantagens de conhecer bem a coleção, pesquisar permanentemente de modo a enriquecer o tema e assegurar a conservação da coleção, logo, passa a ser um especialista em determinado tipo de produção artística ou cultura. No entanto, Rupp alerta para o risco de este curador aplicar "uma concepção tradicional de curadoria, articulando exposições conforme critérios rígidos com a história e com a cronologia”, o que resulta num contrato de "fiel responsável pela coleção". 
No interim, cabe discutir a curadoria consolidada como uma das dimensões do sistema de arte utilizando discursos de especialistas como medida de conceituação de suas práticas, como identifica Cinara Barbosa (2013: I35-136), que analisa "as circunstância que contribuíram para essa afirmação na atualidade da curadoria". Neste caso, é possível ainda "tangenciar as relações de saberes e poderes situadas no exercício desta atividade". Barbosa observa esse poder como uma relação de força, logo, não depende necessariamente de objeto ou sujeito, pois se estabelece estrategicamente pela capacidade de singularização de determinadas questões, na medida em que é capaz de propor uma ação (a do curador) sobre outra ação (a do artista) de modo a provocar outras possibilidades de reflexão.

Em suma, Barbosa considera que "toda curadoria pode ser arbitrária, na medida em que segue critérios e escolhas parciais, mas nem todo curador precisa ser autoritário" e reivindica esse pertencimento do mundo da arte ao artista e ao seu processo de produção (Barbosa, 20I3: I46). Neste sentido percebe-se claramente um incômodo comum entre a museologia - como área de conhecimento - e o artista - que não pode ser considerado mais uma das dimensões do campo da arte se não for a principal: Em que medida os intermediários (museu e curador, neste caso) entre a obra e público são desejáveis ou necessários?

A dificuldade de alguns movimentos artísticos em unir a "experimentação com herança pré-moderna com a simbologia popular", foi observada por Nestor Garcia Canclini (2013: 99), ao estudar a relação entre artistas intermediários e público. Ele identifica a limitada capacidade de difusão e compreensão da arte via mídias e outros meios de comunicação massivos uma vez que a irregularidade e fugacidade de sua ação é ineficaz na criação de hábitos culturais duradouros. O museu, neste caso, é visto como equipamento cultural da sociedade moderna através do qual é possível distanciar-se do passado, que corrói as pretensões de ruptura absoluta rumo à modernidade.

Há dois tipos de críticas, uma que pode ser chamada de 'culta'3 e outra democrática. Segundo a primeira, contextualizar as obras prejudica a contemplação desinteressada que deveria caracterizar toda a relação com a arte. Os esforços didáticos reduziriam a obra ao contexto, a forma ao funcional, a relação empática com uma cultura incorporada na família e na escola à informações explicadas com informações apreendidas em museus desencantados. Tanta pedagogia elimina a cumplicidade dos educandos com seu próprio capital cultural. (Canclini, 20 I 3: I36).

Nesse sentido, a hegemonia - cujo foco é o consumo da cultura - é apontada como o problema central do público da modernidade. Como ação de democratização, em outro estudo, Canclini propõe um "Museu para a globalização", cujo recorte se desenha a partir dos paradoxos e as incoerências sobre a produção e o consumo, o medo e a espetacularização da violência exercendo, ele mesmo, a função de intermediário, ao propor curadoria, que é uma ação intermediaria, num espaço, ainda que imaginário, que é intermediário: o Museu.

Pela multiplicidade de significações da palavra curadoria ao longo do seu processo histórico, Hans Obrist (2010) optou por fazer um recorte temporal que circunscreve as décadas de 1970 e 1980, quando, segundo o autor, ocorreu uma intensificação dessas práticas artísticas experimentais e contraculturais nas instituições museais, o que tangencia com uma importante questão dos domínios do sistema da arte: a legitimidade da obra de arte.

\footnotetext{
${ }^{3}$ Ser culto é "reprimir a dimensão visual em nossa dimensão perceptiva com o mundo e inscrever sua elaboração simbólica em um registro escrito" (Canclini, 2013: 143).
} 
Segundo Giulio Carlo Argan (1994: 19-20) a autenticidade de uma obra de arte é decidida pela sua qualificação e depende da "noção histórica", sobretudo para afastar possibilidades de repetições ou falsificações, conformidade com modelos preestabelecidos e operações técnicas separadas do ato conceptivo. Ou seja, a evolução do processo legitima a obra e também se coloca como critério de autenticação.

De outro modo, os processos de patrimonialização, musealização e crítica de arte desempenham papel de legitimadores da obra de arte, por se caracterizarem como instituições que atendem aos interesses do Estado ou do mercado de arte podendo promover um furo na autenticação da obra a partir de critérios estéticos, estilístico ou históricos que a qualificam. Portanto, podese considerar a hipótese de que o museu, como instituição oficial a serviço da sociedade (representada pelo Estado) pode ser compreendido também como uma das dimensões do sistema de arte.

A curadoria como ação de reversão pode ser delineada a partir da transição entre a Tradição dos Salões da Academia Imperial francesa e o Salão dos Independentes realizado pelos artistas recusados - os Impressionistas - imprimindo novos rumos à arte. Tais antecedentes também conduzem à observação dos processos curatoriais a partir das influências conjunturais e contextuais tais como: ideias iluministas, positivistas, racionalistas e cientificistas; ideologias culturais; vanguardas artísticas e revoluções tecnológicas.

Nesse sentido, Dominique Poulot observa que no contexto pós Revolução Francesa, a arte é liberada e funda-se a política cultural do Estado Frances, onde, "o museu se tornou paralelamente uma engrenagem do sistema das Belas Artes a serviço da prosperidade pública e do gosto nacional, assim como da consolidação do regime, graças a intervenções 'políticas'." (2013:91).

Outro aspecto que indica o caráter legitimador do museu é sua dimensão memorialista na formação de seus acervos e na elaboração de narrativas a partir destes. Como guardião da memória, o museu tem contribuído de forma arbitrária, já que legalista, com a consolidação de hegemonias e, por consequência, da segregação de grupos, culturas e produções artísticas contra hegemônicas. Segundo Jaques Le Goff (2003: 426),

tornarem-se senhores da memória e do esquecimento é uma das grandes preocupações das classes, dos grupos, dos indivíduos que dominaram e dominam as sociedades históricas. Os esquecimentos e os silêncios da história são reveladores desses mecanismos de manipulação da memória coletiva.

O universo da memória está presente no campo dos museus e da museologia, por isso mesmo Mario Chagas (2010:3) defende que "o diferencial não está no reconhecimento do poder da memória, mas sim na colocação desse poder a serviço do desenvolvimento social" e dos grupos sociais menos favorecidos, de modo a garantir a estes o direito à memória e, a partir dela, à construção de suas próprias narrativas. Esse pensamento sintetiza as atuais ideias de museologia social que sustentam os processos e práticas em espaços museais alternativos.

Nesse contexto, cabe à museologia social avalizar a auto representação de grupos contra hegemônicos tanto nas formações de coleções, pelo direito de decidirem o que será preservado, como na concepção de suas exposições. Interessa-nos, neste caso, analisar as abordagens temáticas e a subversão da ordem do discurso e as formas de representações hegemônicas nas exposições. Para Michel Foucault (1999, pag. 8-9), conhecemos, por certo, na nossa sociedade, "procedimentos de exclusão", sendo o mais evidente e peculiar deles, a "in- 
terdição" e ressalta o "perigo" que há no fato das pessoas enunciarem suas falas livremente e "seus discursos proliferarem indefinidamente". $O$ discurso para Foucault está na ordem das leis que cuidam de sua aparição, logo, ele supõe que em toda sociedade a produção do discurso seja controlada, selecionada, organizada e redistribuída por certo número de procedimentos que tem por função conjugar seus poderes e perigos, dominar seu acontecimento aleatório, esquivar sua pesada e temível materialidade. (Foucault, 1999: 9).

Dessa forma, a interdição da fala se comporta como forte instrumento de consolidação e sustentação de hegemonias, uma vez que grupos sociais em situação de subordinação em relação a outros grupos, tendem a seguir a visão de mundo daqueles em detrimento de suas próprias realidades, pois é a que prevalece. Neste sentido, segundo Ana Rodrigues Alves, a importância de estabelecer uma direção cultural e ideológica deve estar conciliada à formação de classes dirigentes que possam se manter "pelo consentimento das massas e não apenas pela força coercitiva" (Gramisci apud.Alves, 2010: 73).

A curadoria tem buscado articular discursos plurais e possibilitar o diálogo entre público e obra ou tema abordado, além de abrir espaços para reflexões, releituras, reinterpretações e novas proposições expográficas. Como instrumento de articulação metalinguística e multidisciplinar, a curadoria dilata-se para metacuradoria, que vale-se do discurso crítico e da multidisciplinaridade teórica e prática na elaboração de exposições. A metacuradoria tanto quanto a museologia social, são tendências contemporâneas que anunciam campos de conhecimento transdisciplinares e podem apontar para uma quebra de paradigmas cristalizados da arte e da museologia.

\section{Processos de museologia social na Estrutural, Distrito Federal}

$\mathrm{Na}$ identificação prévia dos estudos de caso recorreremos a alguns exemplos de experiências desenvolvidas na Casa dos Movimentos da Estrutural, DF, entre 2009 a 2014 (fig. I), sem a pretensão de esgotar o tema, uma vez que o que apresentaremos são fragmentos de processos contínuos, ainda que irregulares.

A Estrutural é uma cidade satélite que se desenvolveu em meados de 1960 entre as margens da Via Estrutural ${ }^{4}$ e o aterro sanitário de Brasília que fica em área ao lado do Parque Nacional e a poucos quilômetros da Praça dos Três Poderes, símbolo maior do poder do Estado brasileiro, o que não minimizou as tentativas de invisibilização da cidade, dos seus moradores e, por consequência, de suas reivindicações por melhorias habitacionais. Segundo Caroline Soares Santos (2013: 23), socióloga, pesquisadora e moradora da Estrutural, o povoamento da cidade teve início em razão da "riqueza do lixo" que era despejado nas imediações e se constituiu como o "grande atrativo da cidade", compreendido como uma oportunidade, por mais penoso que fosse o trabalho de separação.

Desde então, a área passou a receber um grande contingente de pessoas e a antiga invasão, em um curto período de tempo, se tornou uma cidade com uma população de cerca de 40 mil habitantes, segundo o censo do IBGE de 2010. Ainda segundo Santos, a história da Estrutural pode ser contada com base na regularização ou seu reconhecimento como área de interesse social, a partir da qual se iniciaria o diálogo do seu projeto de urbanização. Entretanto, como a cidade está em constante movimento e transitoriedade, o que torna as questões provisórias, a própria regularização não excluiu a atualidade da discussão

\footnotetext{
${ }^{4}$ A Via Estrutural é forma mais comum de identificar a DF-095, oficialmente denominada Estrada Parque Ceilândia (EPCL), construída em 1970.
} 
sobre a remoção ou fixação de famílias da cidade ou mesmo o debate sobre sua viabilidade ambiental.

Esse "caráter transitório" é acompanhado pelos moradores atentos e explica a forte politização da cidade, o grau de organização dos movimentos, a existência de tantos líderes, articulações e principalmente, a impossibilidade de definir a condição política da cidade de uma vez por todas: a configuração pode se transformar a qualquer momento da forma mais imprevisível. (Santos, 2013: 3).

Apesar de transparecer, num olhar menos atento, que as lutas da Estrutural se resumem ao direito à moradia, Santos questiona "quais as lutas políticas cotidianas dessa cidade e qual sua dinâmica? Em que medida as teorias construídas a partir desse lugar envolvem uma ressignificação de práticas e um conteúdo normativo da luta por direitos?". Essas questões oferecem as bases para uma reflexão analítica à cerca da conjuntura social mais complexa que envolve, acima de tudo, uma luta política de abrangência sociocultural.Vale ressaltar que o próprio sentido de "conquista" atribuído aos serviços e obras públicas feitas pelo Estado na cidade Estrutural conduz ao entendimento de que aquele é um direito que foi "tomado à força" (Santos, 2013: I83).

Nesse contexto politicamente favorável havia em comum o desejo de viver com maior qualidade de vida - neste caso, traduzida na garantia dos direitos básico à moradia, saneamento básico, educação e saúde - dos moradores da cidade, entendendo estes como o maior patrimônio a ser preservado e posto a serviço do desenvolvimento local. Ao longo dos dez últimos anos, movimentos sociais aproximaram-se da Estrutural para somar esforços a exemplo do Círculo Operário do Cruzeiro - COC-DF ${ }^{5}$, que atua na educação popular de jovens e adultos e montou vários círculos de cultura com base na metodologia de Paulo Freire, de modo a valorizar a história de vida das pessoas e do lugar.

A partir de muitas ações, reflexões e de reflexões sobra as ações, foi criado o Movimento de Educação e Cultura da Estrutural - Mece que, juntamente com o Coletivo da Cidade e com o apoio do COC-DF participam e coordenam o Pontos de Memória da Estrutural ${ }^{6}$, implantado na Casa dos Movimentos ${ }^{7}$ numa ação conjunta que envolveu técnicos e moradores da cidade, militantes de movimentos sociais ou não, que atuam no local. Isto nos remete ao processo que antecedeu à implantação do Ponto de Memória, entre 2009 a 20I I, quando foram realizadas reuniões periódicas com vistas a sedimentar as bases para a futura criação de um museu comunitário.

A Casa dos Movimentos tornou-se nuclear, à cerca da qual orbitam diversos grupos e movimentos sociais que atuam conjuntamente. Dessa congregação, surgiram outras iniciativas que transbordaram o Ponto de Memória e seu escopo inicial de atuação, como o Banco Comunitário da Estrutural, a Editora Popular Abadia Catadora e a Biblioteca Comunitária Palavras Catadas. Com isso, outros

\footnotetext{
${ }^{5} \mathrm{O}$ Círculo Operário do Cruzeiro - COC, é uma entidade sem fins lucrativos que desenvolve ações voltadas para educação e cultura, desde 2003. Localiza-se no Cruzeiro, região administrativa do Distrito Federal. ${ }^{6} \mathrm{O}$ Ponto de Memória da Estrutural integra o Programa Pontos de Memória criado pelo Instituto Brasileiro de Museus (lbram), em janeiro de 2009 "com o objetivo principal de estimular a ampla participação popular nos assuntos relativos à memória social e aos museus". (Chagas; Rocha; Pereira; Gouveia, 20 I0:2). O Programa tem apoiado iniciativas de museologia social a partir de práticas e processos desenvolvidos em e com grupos sociais que historicamente tiveram seus direitos de registro de memória negados pelo próprio Estado.

${ }^{7} \mathrm{~A}$ Casa dos Movimentos da Estrutural foi aberta a partir de um aluguel cotizado pelos movimentos que utilizam o espaço. $O$ objetivo é atender às diversas ações desenvolvidas pelos grupos e movimentos sociais engajados nas ações pelo desenvolvimento local. Concentra-se principalmente em atividades voltadas para educação e cultura, o que inclui as ações sociomuseológicas que vão de exposições participativas a aulas de capoeira, música, pintura, produção de livros artesanais, dentre outras.
} 
moradores têm, aos poucos, se engajando nas ações. Entretanto restou o desejo de consolidação de um museu comunitário, que tem o objetivo de valorizar a memória e recontar a história desta comunidade a partir de uma narrativa de seus próprios moradores e, a partir dele, desenvolver continuadamente ações que minimizem a problemática social enfrentada diariamente pelos moradores.

Ao longo de sua trajetória, o museu, como equipamento cultural, obteve o poder simbólico de consolidar hegemonias através da evidencia de personalidades políticas e heróis constituídos pela nação que pouco ou nada se aproximam das pessoas e do cenário da Estrutural ou de outras comunidades ou grupos historicamente marginalizados. Mesmo quando representados nos museus, a história desses grupo quase sempre é construída a partir da visão do outro.Assim, o desejo de construção de uma identidade local pautado numa narrativa em primeira pessoa é mais do que legítimo, é necessário, como ação de reparação às desigualdades e injustiças instituídas na estrutura da sociedade.

Enquanto o museu não se consolida, os processos continuam a ser desenvolvidos no âmbito da Casa dos Movimentos, bem como dos demais equipamentos socioculturais e educativos a ela associados conduzindo-nos, cada vez mais, à ideia de que as práticas museológicas não dependem necessariamente do intermédio do museu para que ocorram e apresentem resultados satisfatórios. Nesse sentido, a partir das discussões, rodas de memória e atividades diversas de engajamento social, foi possível elaborar propostas de curadorias participativas, num esforço conjunto de traduzir um discurso coletivo, a partir de memórias individuais que, por sua vez, constituem a memória coletiva.

Dessa forma, a exposição inaugural (20II) foi pensada em sua totalidade como "Movimentos da Estrutural" com o objetivo de valorizar a história da cidade a partir das memórias de luta de seu povo pelo direito à moradia, como também da lida cotidiana da cidade como traço mais marcante da formação de seus moradores.

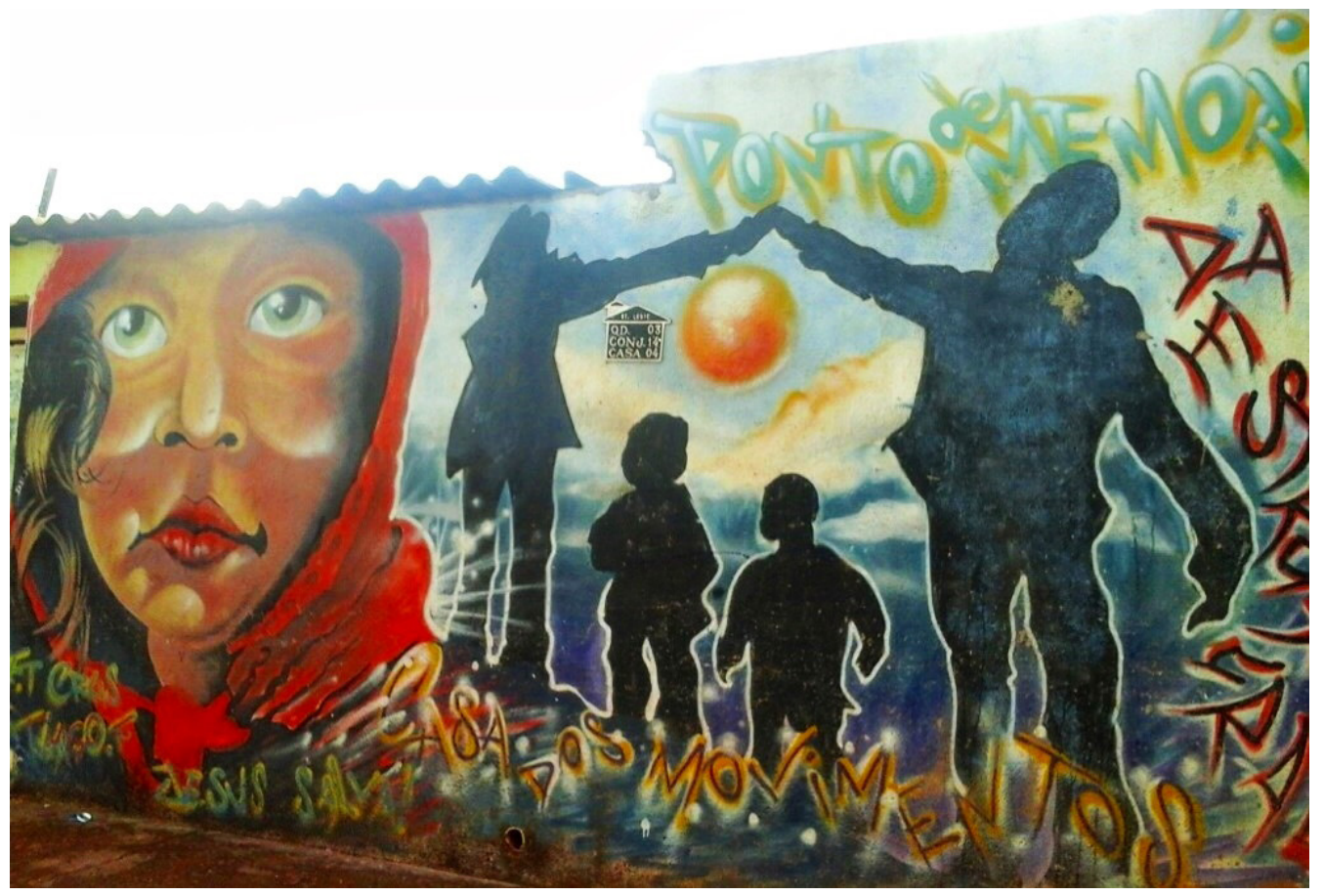

Fig. I. Casa dos Movimentos da Estrutural, DF. Fonte: autora 
Com narrativa construída pelos próprios moradores, de forma não linear, os recortes temáticos para construção do discurso abordariam as soluções para auto sustentabilidade e inclusão social; as mobilizações pela moradia, infraestrutura e reconhecimento por parte do Estado; a educação informal das crianças por meio da ludicidade; e, o papel da mulher na organização social da Estrutural. Os referenciais identificados foram: os movimentos sociais e militantes da cidade, os espaços de trabalho e lazer, as crianças com seus folguedos e brincadeiras, o burburinho da feira, o catador de lixo, o vendedor ambulante, a dona de casa, o grafiteiro e outros artistas urbanos.

Entretanto, devido à falta de espaço e recursos financeiros para realização da exposição em sua totalidade, o tema para a exposição inaugural resultou em: Luta, resistência e conquista - um recorte sobre a labuta pela permanência no lugar, a resistência dos que reivindicam o direito à cidadania e às conquistas obtidas, decorrentes da incessante luta (fig.2). Manteve-se os referenciais identificados inicialmente como ponto de partida para a construção do discurso que foi compactado, num movimento reflexivo de análise e síntese.

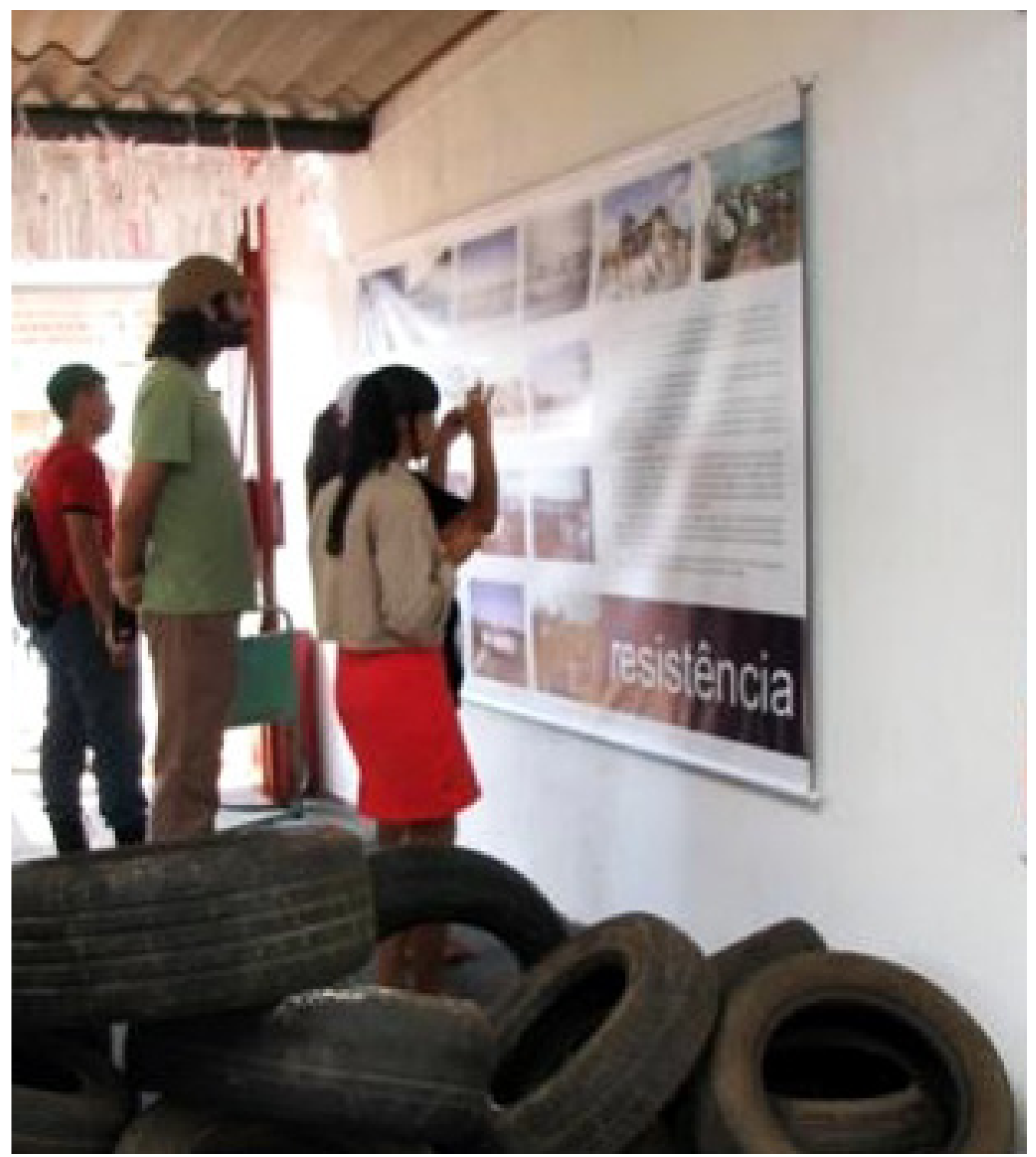

Fig.2. Exposição "Luta, resistência e conquista”. Casa dos Movimentos da Estrutural, DF. Fonte: autora 
Nesse processo, ocorreram inúmeras reuniões de mobilização e sensibilização dos moradores evidenciando a importância da valorização da memória e da história local como meio de justificar a permanência no território especulado pelo mercado imobiliário.A proximidade do "lixão", que motivou a ocupação do território por ser usado como forma de subsistência, foi utilizada como argumento para as investidas de desocupação, bem como a proximidade do Parque Nacional que "poderia" sofrer ameaças ambientais por parte dos "moradores" (não do lixo?) demonstrando incoerência sócio ambiental no trato da questão.

No processo de identificação de acervos, destaca-se o Café com Memória que se caracteriza como uma roda de conversa entre os moradores para compartilhar fragmentos de suas memórias relacionados à formação e cotidiano da cidade. Com o apoio técnico do Curso de Museologia da Universidade de Brasília, a partir do Projeto de Ação de Extensão ${ }^{8}$ desenvolvido junto ao Ponto de Memória da Estrutural, foi possível realizar a segunda exposição participativa intitulada "A Mulher e a Cidade" (20I3-20I4), viabilizada por meio do desenvolvimento do inventário participativo" que identificou mulheres da Estrutural que se destacam pelas suas ações coletivas em prol da comunidade, com vistas ao empoderamento dessas e de outras mulheres envolvidas no processo.

\section{Um altar para as memórias}

A lista de créditos da exposição girava numa chapa de aço chumbada na parede à direita, logo à entrada da pequena sala de aproximadamente vinte metros quadrados, o que a deixava completamente branca como resultado de todas as cores impossibilitando sua leitura imediata. No desacelerar da chapa, é possível ler, mesmo que com certo desconforto, os 33 nomes ${ }^{10}$ escritos em forma de espiral que assinaram a "concepção, curadoria produção e montagem" da exposição. Em ordem alfabética, todos assinaram juntos a construção de uma narrativa de "Luta, resistência e conquistas", o primeiro recorte no universo dos possíveis dos "Movimentos da Estrutural".

Por toda a parede ao fundo da sala, um grafite em preto e branco sintetiza o objeto de memória, a partir do olhar do artista, na figura da criança no canto da trave em posição de defesa do gol, disputando o primeiro plano da composição com seis tonéis enfileirados de três em três no outro extremo; do vendedor de água ambulante, em segundo plano; e, dos barracos feitos com madeira reaproveitada do lixão, mais ao fundo. Em perspectiva. À esquerda do grafite, um tonel, - de verdade - recolhido no lixo e posto em frente ao enfileiramento de tonéis pintados parece saltar do grafite e ganhar tridimensionalidade para contar a história da chegada da água. O cenário foi imaginado pelo artista Tiago Franscisco, também morador da cidade, e traduz-se como uma releitura de mais de 400 fotos da Estrutural feitas em diversos períodos, desde sua formação inicial. O acervo fotográfico em questão foi formado a partir de empréstimos de moradores identificados nas rodas de memória que antecederam a exposição.

\footnotetext{
${ }^{8} \mathrm{O}$ Curso de Museologia da Faculdade de Ciência da Informação da Universidade de Brasília, via Edital FLUEX do Decanato de Extensão, formalizou o Projeto de Ação no Ponto de Memória da Estrutural em 201 I para o desenvolvimento de ações contínuas e integração dos estudantes de museologia e áreas afins, reunindo ensino, pesquisa e extensão.

${ }^{9}$ Inventário participativo, para fins de compreensão deste texto, traduz-se como um método que prevê o desenvolvimento de técnicas e processos de identificação e registro das formas de expressão artísticas, saberes e fazeres locais, histórias e memórias dos moradores e suas relações com o meio ambiente e cultural, com base no Inventário Nacional de Referências Culturais (INRC) do Instituto do Patrimônio Histórico e Artístico Nacional (IPHAN), adaptadas às especificidades locais o que inclui, sobretudo, a participação ativa dos moradores durante todo o processo.

${ }^{10}$ Adoaldo Alencar (Duda),Alessandra Ferreira Araújo,Anísio Nascimento dos Santos, Caroline Soares dos Santos, Cintia Oliveira, Cláudia Storino, Coracy Coelho, Denilson Lima, Deuzani Cândido Noleto, Dianna Amaral, Eneida Braga, Fernanda Araújo, Flávia Pereira, Inês Gouveia, Isabela Guimarães, Jacira de Jesus Vieira, José Silva, Lucas Teixeira, Luciana Palmeira, Marcelle Pereira, Maria Abadia de Jesus, Marijara Queiroz, Mario Chagas, Mirela Araújo, Rafaela Medeiros, Samuel Silva, Sandra Lobo, Sara Schuabb, Simone Kimura, Soraia Costa, Tais Valente, Terezinha Santana,Tiago Francisco,Valdemar de Assis, Vicente de Paula Souza.
} 


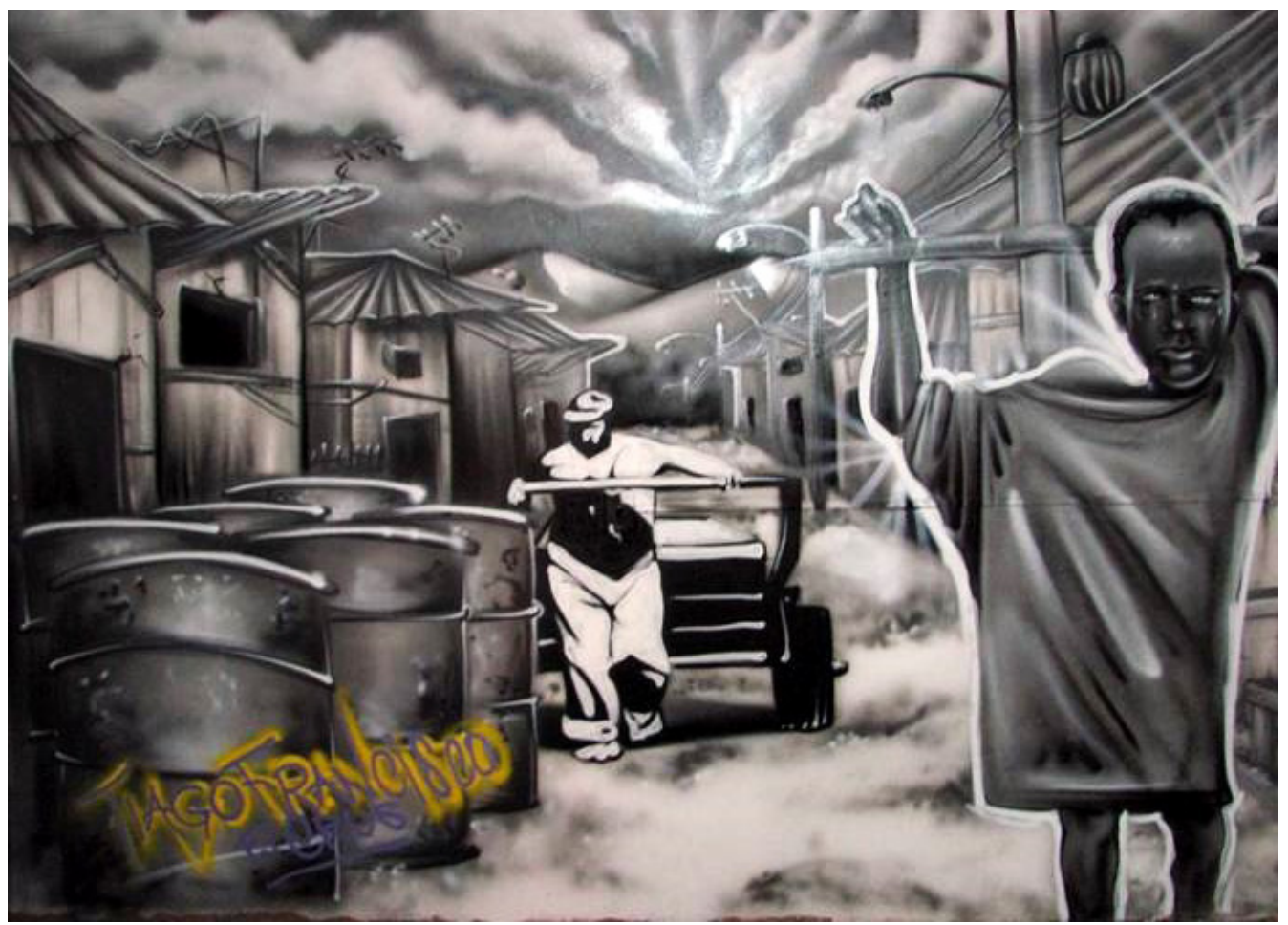

Fig.3. Sala da Memória, Grafite. Fonte: autora

A sala da memória (fig.3), como foi chamada, dispunha ainda de três chapas de metal presas às paredes com imãs de geladeira à disposição; uma estante em grades de metal desamassado e remontado em outra forma distinta da original por faltar partes; e, em frente a este, degraus de uma escada também em metal, que se assumiu como altar da memória. Enquanto esse pequeno conjunto de lixo transformado em suportes expográficos aguardavam seus objetos a destacar, eles próprios, em um diálogo silencioso com o grafite e o tonel que se pronunciava fora dele intermediando a passagem do bi para o tridimensional, protagonizavam a exposição. $\bigcirc$ tempo entre a organização dos suportes e a chegada dos objetos de memória, que viriam das mãos de cada morador após desfilarem em cortejo pela feira e comércio local até a Casa dos Movimentos, em seu ato inaugural, foram essenciais para que a mensagem ficasse clara: há sim riqueza no lixo (fig.4).

O vazio do altar da memória estava repleto de questões a serem elaboradas e reelaboradas à cerca, também, da exposição museológica. Após estaticamente dispostos para se comportar como base/suporte, percebeu-se que os degraus, em proporção ao tamanho da pequena sala, impuseram uma altivez que se aproximava à dos altares religiosos ou espaços de adoração/sacralização, comumente comparados às formas clássicas de expor dos museus. Isso, contraria o pensamento da museologia social que busca a subversão da lógica cristalizadora e fetichista do museu em seu modelo mais convencional?

Segundo Betinna Rupp, que discorreu sobre "a atividade do curador enquanto autor de exposições", a exposição ativa o poder de definição do objeto tirando-o da letargia de modo a atribuir valores mercadológicos. Ao observar a obra Le vide de Yves Klein, que acabou colocando em cheque o valor que a obra adquire na exposição, Rupp identifica que o artista

promoveu o vazio (que logo ficou cheio de convidados) retirando todos os móveis da Galeria Iris Clert, não foi apresentado um objeto, mas a própria exposição era o objeto artístico. [...]. Ao não expor nada, o artista convidou o público a refletir sobre a imaterialidade da arte e, indiretamente, sobre a valorização que as obras adquirem ao ser expostas (20II: I3 I-I32). 


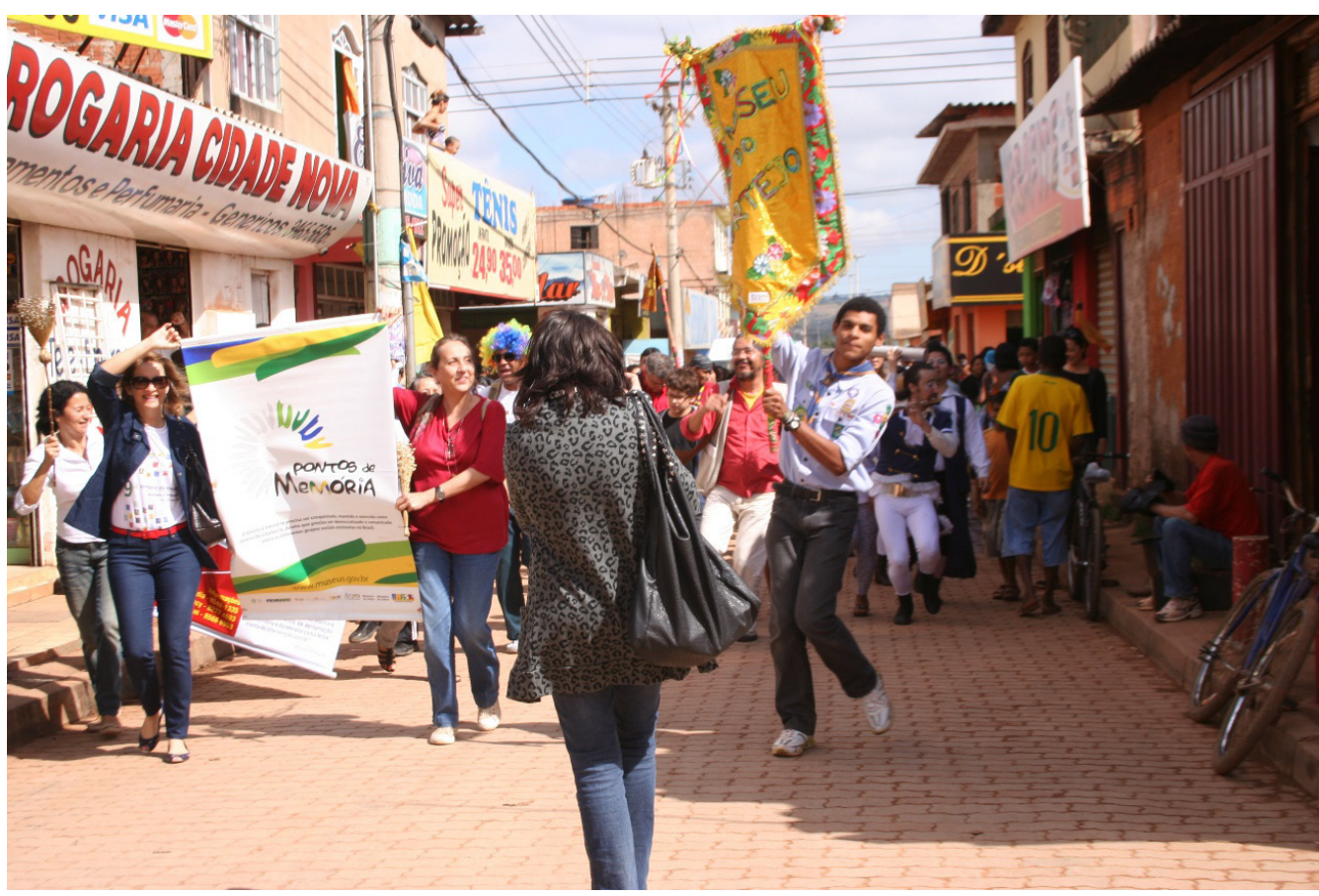

Fig.4. Cortejo Inaugural da Casa dos Movimentos, Estrutural, DF. Fonte: autora.

No refluxo, subvertendo a ordem do discurso e da lógica classificatória dos museus, que tem como pratica hierarquizar coleções, geralmente com critérios baseados no padrão hegemônico de sociedade - homem, branco, rico, heterossexual - o altar da memória se assumiu também como obra aberta, ao contar com a imprevisão e a transitoriedade da sua carga, que também lhe dará forma, ou the consagrará como espaço de reflexão/transformação. $O$ altar da memória é, também, neste caso, para ser imaginado.

Uma vez assumido, o altar da memória transbordou do suporte para a sala inteira, o que confirma o texto de apresentação da sala que vale a pena reproduzir na íntegra:

Esta sala acolhe a memória nossa, moradores e moradoras da Estrutural, memória que se traduz num objeto, numa foto, pedaços de nós mesmos que lembram momentos tristes, momentos sofridos, momentos de lutas, de resistências, de alegrias. Objetos aqui expostos que eternizam nossas experiências e vivencias e que nos remetem de volta aos dias idos, às lutas por um lugar para morar, por um lugar nosso, marcado por nossas histórias. Os nossos objetos que desfilaram no cortejo significaram a união mais uma vez em nossas vidas, agora para reviver o nosso passado, para que possamos sentir mais o presente e construir um futuro de conquistas, e para que não nos esqueçamos disto, consagramos as nossas lembranças no altar das nossas memórias, para que os nossos descendentes saibam do seu passado e da importância deste lugar que hoje é a nossa casa no mundo. (Ponto de Memória da Estrutural, 2015: 375).

cortejo ao qual o texto se refere, trata-se de uma ação que pode ser descrita como uma performance museal conduzida pelo estandarte que a denomina de "Museu de Cortejo"". Podemos descrever esse ato inaugural da expo-

"O Museu de Cortejo é uma ação que pode ser entendida como performance museal. Idealizado pelo Professor, museólogo e poeta Mario de Souza Chagas. Como exemplo, o Museu de Cortejo percorreu em "clima contagiante de alegria, com cerca de 80 pessoas, o Fórum Nacional de Museus" onde também desenvolveu uma ação performática com membros dos Pontos de Memória, em 2010. Em: https://www. youtube.com/watch?v=BhGGPJsnEKg. 
sição como uma espécie de procissão de moradores e associados carregando em mãos seus objetos de memória, ao tempo que dançavam e entoavam cantos de convite para ampliação da ação conjunta que findaria na sala da memória da Casa dos Movimentos. Foram esses objetos que romperam com o fecundo diálogo entre os suportes resignificados e à sua própria condição de produto industrializado, lixo ou objeto museal, rompendo o vazio. Nesse sentido, cabe lembrar Boaventura de Souza Santos (2002: 246) quando diz que o "objectivo da sociologia das ausências é transformar objetos impossíveis em possíveis e com base neles transformar as ausências em presenças".

Nesse sentido, o lixo tem educado. Talvez não seja o lixo propriamente dito mas toda a reflexão que dele gera, no sentido de formação de valores mais humanos, sobretudo voltados para as questões do meio ambiente. De acordo com o texto assinado pela Equipe de Coordenação do Ponto de Memória da Estrutural (PME), também de autoria coletiva, (2015: 379), a relação dos moradores com o lixo não se limita ao trabalho, pois imprime um estilo de vida e uma relação diferente com a natureza. No entanto, a transitoriedade política não garante a permanência no local o que gera instabilidade e o sentimento de não pertencimento ao lugar e, por mais que ensaiem um menosprezo ao lixo, O fato do lixo ainda estar lá talvez seja um dos motivos para que ainda não tenham sido, de vez, arrancados dali. Como diz Creuza, o lugar é de rico, mas por enquanto os ricos não saberiam lidar com essa proximidade do Lixão, porque não é essa a história deles.

A sala de memória como destino final do cortejo foi definida, ainda que não em definitivo, pelas pessoas que desfilaram com seus objetos de memória, de modo a interagir com a curadoria, intencionalmente participativa, da exposição. Para a inauguração, seria necessário ainda retornar ao portão de entrada, onde Tiago Francisco fazia os acabamentos finais do grafite que registraria não apenas o nome - Ponto de Memória e Casa dos Movimentos da Estrutural na faixada, mas também as expressões que permeiam a cidade "como hip hop, brincadeiras de rua, o trabalho duro e a desconfiança da polícia". Antes, seria necessário atravessar o hall de entrada sobre a recriação de uma pista asfaltada, mas não sem observar a fachada da pequena casa que abriga a Sala de Memória faceada com o "diário oficial do Distrito Federal, que traz o nome dos cidadãos que conquistaram um lote na cidade, um sonho distante conquistado a custa de muita luta, muitas disputas políticas e algumas vidas" (PME, 20I 5: 374).

A próxima etapa para finalmente alcançar o portal de entrada seria desviar da pilha de pneus usados que dividia os núcleos expositivos sugerindo uma circulação, ao tempo que representava uma das formas mais comuns de luta e de resistência na cidade, que consistia em fechar aVia Estrutural de modo a chamar atenção para suas questões. Do teto, pendia rabiolas de uma pipa gigante que a tinha tripla função de representar o universo lúdico, educativo e imaginário das crianças, tão presentes no cenário da Estrutural, desviar o olhar para o todo e disfarçar imperfeições do teto. Dessa forma, a exposição só poderia ser inaugurada de dentro para fora, pois fora pensada de fora para dentro.

Contudo, após o ato inaugural, a Casa dos Movimentos deveria continuar a atender às demandas de suas reuniões, rodas de memória, dinâmicas de grupo (fig.5), aulas para alfabetização de adultos, oficinas de encadernação de livros e atividades culturais e artísticas diversas em função dos movimentos e pessoas que ali orbitavam, para além da exposição, o que lhe atribuía ainda mais o caráter de instalação. 


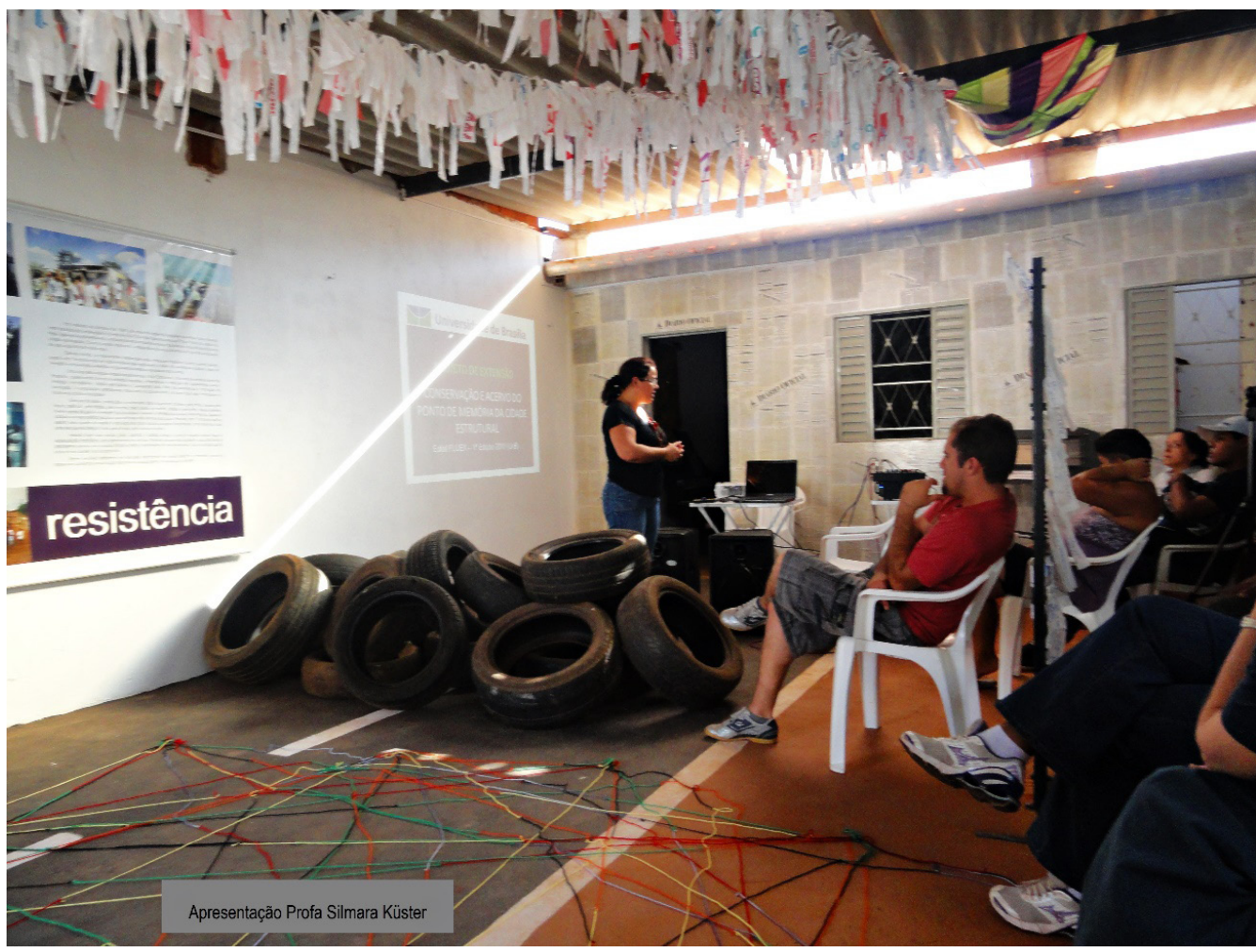

Fig.5. Reunião e dinâmica da Casa dos Movimentos. Apresentação da Profa. Silmara Küster, Estrutural, DF. Fonte: autora.

No conjunto a exposição falava sem textos, numa aproximação às instalações que, segundo Luciana Bosco e Silva, se apresentam de forma efêmera já que depende de uma relação espaço temporal para existir e acrescenta que

A evidência desse espaço, do lugar instalado, onde a obra efetivamente acontece, é a consciência do espectador da obra em si. A construção dessa verdade espacial, que se completa através de seu negativo, dos vazios existentes, da percepção do todo, através de uma consciência maior de espaço-tempo, onde espaço, vazio e tempo se fazem presentes e essenciais à existência da própria obra, em conjunto com a percepção da mesma pelo espectador, constituem o âmago da Instalação (2012: 229).

A conciliação do cortejo, que percorreu ruas e feira, ao contexto de instalação, promoveu o que Coelho Neto denominaria de "entropia", sendo esta "a medida da desordem introduzida numa estrutura informacional" o que estabelece uma contradição, pois, para a teoria da informação,"a informação ideal é a que tende para o máximo de originalidade”. Entretanto,"quanto mais imprevisível [ou original] for uma mensagem, menos será ela passível de apreensão" sobretudo para quem tem a informação como uma "medida de ordem" e, por consequência, observa o novo e o original, com "nítidas características de desordem, de confusão, de complexidade". Dessa forma, a novidade é vista como "a introdução da desordem numa estrutura preexistente". (Coelho Neto, 1973: 21).

A partir de Coelho Neto podemos considerar ainda que as reações entrópicas dilatam as possibilidades de análise do objeto a partir da "informação estética", caracterizada pelo conhecimento por meio do sensível, intuitivo ou primacial, ao transbordar o campo da "informação semântica", que se relaciona mais com a compreensão por meio da razão.

Com base na definição contextual de Silva, "intervenção urbana" é um diálogo estabelecido com o espaço urbano, em geral provisório e efêmero, definição esta que também poderia ser utilizada para compreender o Museu de 
Cortejo que não apenas divulgou a exposição ou o Ponto de Memória, como, ele próprio, passou a compor o que poderíamos chamar de ação expositiva ou objeto da memória posta ao alcance das mãos. Poder-se-ia, neste caso, considerar uma performance? Ainda segundo a autora, "o artista plástico Tunga prefere o termo "Instauração" no lugar de performances ou Instalação. Ele afirma que este termo definiria de maneira mais satisfatória algo que a partir daquele ato começa a existir" (Silva, 2012: I38).

Neste caso, as linguagens artísticas representam fortes elementos de "informação estética" ao tempo que mediam público e exposição, especialmente as que se delineiam a partir de um tema e não de uma obra ou acervos. Dessa forma, a arte em suas diversas linguagens, sobretudo no que se refere àquelas que cercam o caso aqui apresentado - performances, instalações, intervenções urbanas ou "instauração" - passam a servir aos interesses representativo da exposição? Estaria a arte, neste caso, no papel de mediadora do discurso?

Destarte, dilatamos a noção de curadoria para metacuradoria que, a partir das observações até aqui feitas, é uma prática que tem se colocado no campo da museologia social, que, por sua vez, apresenta resultados de suas experiências cada vez mais próximas à metalinguagem da arte contemporânea, sobretudo no que se refere às instalações, intervenções urbanas e performances, artísticas ou culturais.

\section{Considerações finais}

A exposição museológica é o principal meio pelo qual o museu intermedia a comunicação entre as obras/temas e seus públicos, caracterizando-se ainda como instrumento potencializador do desenvolvimento de pesquisas e de processos educacionais nas instituições museais. Entretanto, o museu, como equipamento cultural moderno, tem na sua trajetória histórica, o poder de legitimar povos, culturas, narrativas e obras de arte através de seus conteúdos materiais e imateriais, o que, em geral, tem contribuído para reforçar hegemonias.

Nesse sentido, faz-se necessário buscar novas propostas curatoriais que estejam em consonância com as práticas da museologia social, o que se manifesta como um rompimento não apenas na forma de conceber, mas na forma de materializar o discurso. É evidente que os processos de metacuradoria desenvolvidos no contexto aqui apresentado requerem um tempo mais dilatado para comportar maior participação, exatamente por terem como prática a valorização do processo como experiência que qualifica o produto. Neste caso, estamos mais uma vez em sintonia com Santos que nos propõe operar na "sociologia da ausência" e da "emergência" de modo a dilatar o presente - que não deve ser "entrincheirado entre passado e futuro" - e comprimir o futuro - repleto de expectativas e possibilidades nem sempre reais - o que torna o presente fugaz. Portanto, um "futuro melhor" não deve estar distante, mas na reinvenção do presente "tornado coerente pelo trabalho de tradução" que, por sua vez, permite criar sentido e direções precárias, mas concretos, de curto alcance, mas radicais nos seus objectivos, incerto, mas partilhados. O objectivo de tradução entre os saberes é criar justiça cognitiva a partir da imaginação epistemológica. $O$ objectivo da tradição entre práticas e seus agentes é criar as condições para uma justiça social global a partir da imaginação democrática. (Santos, 2002: 274).

Cabe ainda observar em que medida essas experiências permitem a reflexão sobre práticas tradicionais de curadorias de modo a estabelecer novos paradigmas (meta)curatoriais onde prevaleça a tendência participativa na tomada de decisões, a construção de pensamento processual, narrativas plurais 
e autoria coletiva. No estreitamento com a metacuradoria,"alinhavar discursos diversos a partir de um fio condutor, dando origem a um discurso plural, mas preservando a singularidade de cada elemento que o integra". A metacuradoria pode "promover o debate entre obras independentes", criando um ambiente de mediação de modo a possibilitar releituras e recriações metalinguísticas.

Fica, pois, o desejo de articular as diversas questões aqui elencadas com o propósito de analisar as abordagens temáticas, a construção de discursos metacuratoriais e suas formas de representação nas exposições pensadas no âmbito da museologia social, de modo a possibilitar ainda o delineamento histórico desses processos e práticas contemporâneas, bem como suas transformações conceituais e ideológicas. Para além, pode ser uma tradução das linguagens comumente usadas nas artes visuais, sobretudo na arte conceitual, para o campo da museologia desenvolvida na prática social.

\section{Referências}

ALVES, Ana Rodrigues Cavalcante. $O$ conceito de hegemonia: de Gramsci a Laclau e Mouffe. Lua Nova: São Paulo, 80: 7I-96, 2010.

ARGAN, Giulio Carlo \& FAGIOLO, Maurizio. Guia de história da arte. $2^{\mathrm{a}}$ Edição: Lisboa: Editorial Estampa, 1994.

BARBOSA, Cinara. A era da curadoria. Revista Museologia \& Interdisciplinaridade. Brasília: UNB: FCI:Vol. II, p. I35- I47, n4, maio/junho de 2013.

CANCLINI, Nestor Garcia. Culturas Híbridas. (Trad. Ana Regina Lessa). $4^{\mathrm{a}}$ Edição: São Paulo: Edusp, 2013. (Coleção Ensaios Latino Americanos).

CHAGAS, M.; ROCHA, E.; PEREIRA, M.; CONALGO, E. SILVA, C. R.;ALBERNAZ, P.; GOUVEIA, I.; e, TOLEDO,W. Vontade de memória, vontade de museus: a experiência do Programa Pontos de Memória. Ibram: Brasília, 2010.

CHAGAS, Mario \& GOUVEIA, Inês. Museologia Social: reflexões e práticas (à guisa de apresentações). In: Museologia Social. Chapecó: Cadernos do CEOM: Ano 27, $\mathrm{n}^{\circ} 4 \mathrm{I}, 2015$.

COELHO NETTO, José Teixeira. Dicionário Crítico de Política Cultural. São Paulo: lluminuras, 2004. . Introdução a teoria da informação estética. Vozes: Petrópolis, 1973.

FOULCAULT, Michel. A ordem do discurso. (Trad. Laura Fraga Sampaio). $5^{a}$ Edição: São Paulo: Edições Loiola, 1999. (Aula inaugural do College de France, pronunciada em 2 de novembro de 1970).

INSTITUTO BRASILEIRO DE MUSEUS. Museália. Revista de cultura e museus. Brasília, $\mathrm{n}^{\circ} \mathrm{I}$, ano I, dezembro, $20 \mathrm{I} 0$.

LE GOFF, Jacques. História e Memória. Campinas: Ed. Unicamp, 2003.

OBRIST, Hans Ulrich. Uma breve história da curadoria. São Paulo: BEl Comunicação, 2010.

POULOT, Dominique. Museu e Museologia. (Trad. Guilherme João de Freitas Teixeira). Belo Horizonte:Autêntica, 2013.

QUEIROZ, Marijara S. Museologia. Brasília: UNB, 20I5. 45 p.: il. - (Coleção Nas trilhas do patrimônio cultural; v. I).

RUPP, Bettina. $O$ curador como autor de exposições. Revista-Valise. Porto Alegre, vol. I, $\mathrm{n}^{\circ} \mathrm{I}$, ano I, julho de $20 \mathrm{II}$. 
SANTOS, Boaventura de Souza. Para uma sociologia das ausências e uma sociologia das emergências. Revista Crítica de Ciências Sociais. Coimbra, n 63, p. 237 280, outubro, 2002.

SILVA, Luciana Bosco e. Instalação: espaço e tempo. Escola de Belas Artes: UFMG: Belo Horizonte, 20I2. (Tese de doutoramento).

SOARES, Caroline Santos. Área de risco ou área de rico: teorias sobre política, direito e respeito na Cidade Estrutural. UNB: Departamento de Sociologia, 2013. (Tese de doutorado).

\section{Fontes eletrônicas consultadas}

Instituto Brasileiro de Museus (lbram) - http://www.museus.gov.br - último acesso em 8/5/2016.

Instituto de Estudos Avançados da Universidade de São Paulo (IEA-USP) http:// www.iea.usp.br/iea/metacuradorias - último acesso em 7/5/20l6.

Ponto de Memória da Estrutural - http://memoriaestrutural.blogspot.com.brl último acesso em 8/5/2016.

https://www.youtube.com/watch?v=BhGGPJsnEKg; acesso em 10/6/2016. 